\title{
Formation of Function Use Cases Based on Its Mathematical Model
}

\author{
Vasyltsova Nataliia ${ }^{1}$ \\ Panforova Iryna ${ }^{2}$
}

Kuzma Yelyzaveta ${ }^{3}$

\author{
${ }^{1}$ Kharkiv National University of Radio Electronics, 14 Nauky Ave, \\ KharkivUA-61166, Ukraine, nataliia.vasyltsova@nure.ua \\ ${ }^{2}$ Kharkiv National University of Radio Electronics, 14 Nauky Ave, \\ KharkivUA-61166,Ukraine, iryna.panforova@nure.ua \\ ${ }^{3}$ Kharkiv National University of Radio Electronics, 14 Nauky Ave, \\ KharkivUA-61166, Ukraine,yelyzaveta.kuzma@nure.ua
}

\begin{abstract}
The analysis of modern research on the problem of formal description of scenarios for the fulfillment of functional requirements is carried out. The research problem is formulated as improving the accuracy of identifying precedents in descriptions of functional requirements. $A$ technique to refine the description of a functional requirement has been developed. The proposed methodology was tested on the example of the function "Formation and maintenance of the individual plan of the department teacher". As a result of testing, the precedents of the function were clarified.
\end{abstract}

Keywords: Use Case diagram, functional requirement, case, mathematical model, individual plan.

\section{INTRODUCTION AND PROBLEM STATEMENT OF THE FORMATION OF FUNCTION USE CASES BASED ON MATHEMATICAL MODEL THIS FUNCTION}

Modern paradigm for describing system requirements is based on the publication of the requirements in the form of scripts. An example of the implementation of a given paradigm using visual models of the Unified Modeling Language (UML) is a model of the requirement provided by Microsoft Corporation [1]. Interest growth in research into the aspects of application of models for requirements engineering shows in [2]. One of area of this researches implies the development and improvement of models and methods of requirements engineering based on the identification and the formal description of knowledge from unstructured and weaklystructured texts. Thus, paper [3] discusses the issues on comparing and merging the elements of a system whose description are published in the form of Use Case diagrams, Activity diagrams, and data flow diagrams. Article [4] addresses the issue of converting the publications on requirements by rightsholders in an executable system model using behavior models by applying the Activity and State diagrams of UML. Solving the tasks on analyzing the requirements to IS, the description of which employed the UML class diagrams, was considered in [5]. Formal description of Use Case Diagram is given in [6].

However, the question remains open of how to highlight individual cases in the description of scenarios for fulfilling functional requirements. Existing recommendations do not allow us to formulate a general rule for the formation of precedents in the analysis of weakly-structured texts. Therefore, it should be recognized necessary to conduct a special study to find ways to identify cases in the description of the functional requirement scenario.

\section{PROBLEM SOLUTION AND RESULTS}

The main problem of modeling precedents based on a textual representation of a subject area is the problem of blurred perception of individual fragments of this representation. Such a blur occurs due to the presentation of individual fragments of the text as separate precedents. This representation cannot be clarified until an analysis of the actions sequence of the investigated scenario is carried out.

To clarify textual representations in the process of collecting requirements, it is proposed to conduct a study of the structure of mathematical models describing the subject area. In the course of this study, it is proposed to describe each term or factor of the mathematical model, which has independent significance, with separate precedents on the Use Case diagram.

Most often, mathematical models of the subject area are presented in the form of equations or inequalities. Therefore, a study was conducted on the highlighting of precedents of the functions of the organization's management system based on text descriptions and mathematical models of these functions. As a result of the research, a technique for clarifying the description of a functional requirement is proposed. A generalized algorithm for performing this technique consists of the following steps.

Step 1. Separation of the document under study into its component parts.

Step 2. Designation of each part of the document as a separate element of the mathematical model and determination of the type of this model (additive or multiplicative).

Step 3. Analysis of the possibility of detailing the presentation of each element of the model as separate equation or inequality. If this is not possible, go to Step 5 .

Step 4. Record detailed representations of the elements of the mathematical model and return to Step 3.

Step 5. Record the final presentation of the mathematical model of the document and highlight cases based on it. Clarify the previously highlighted list of cases. Completion of the algorithm.

Consider the application of this technique in the development of the functional task "Formation and maintenance of the individual plan of the department teacher". As a result of Step 1, it was found that subject area of this task can be represented by the "Individual Plan" document, which consists of six separate parts:

- position and stake;

- education work;

- educate-methodical work;

- scientific work;

- organizational and educational work; 
- final distribution of time by type of work for the academic year.

During the implementation of Step 2, it was found that the last part of the Individual Plan document is an additive equation, which is a mathematical model of the remaining parts of this document. Therefore, the result of Step 2 is represented by the following equation:

$$
\alpha_{e} C_{e}=T_{1}+T_{2}+T_{3}+T_{4}
$$

where $\alpha_{e}-$ is part of teacher's rate; $C_{e}-$ is quantity of hours allocated for one teacher's rate for the planned academic year; $T_{1}$ - is quantity of hours of education work planned for the academic year; $T_{2}$ - is quantity of hours of educatemethodical work planned for the academic year; $T_{3}-$ is quantity of hours of scientific work planned for the academic year; $T_{4}-$ is quantity of hours of organizational and educational work planned for the academic year.

During the implementation of Step 3 and Step 4 it was established:

- when planning education work, you should consider:

- types of academic disciplines;

- types of flows in which groups of students are combined;

- types of academic work (lectures, practical exercises, laboratory work, etc.);

- when planning educate-methodical work, you should consider:

- types of methodological work that must be performed for successful completion of the academic work;

- types of methodological work that needs to be done to improve quality of academic work.

Therefore, (1) as a result of Step 3 and Step 4 was converted to the following equation:

$$
\begin{gathered}
\alpha_{e} C_{e}=\sum_{a=1}^{k} \sum_{b=1}^{l} \sum_{c=1}^{m} t_{a b c}+\sum_{d=1}^{p_{1}} t_{d}+\sum_{f=1}^{p_{2}} t_{f}+ \\
+\sum_{g=1}^{r} \frac{\alpha_{g} t_{g}}{q_{g}}+\sum_{i=1}^{s} t_{i}
\end{gathered}
$$

where $t_{a b c}$ - is quantity of hours of academic work that is planned to groups of students and to academic discipline; $t_{d}-$ is quantity of hours of methodological work that is planned to successful completion of the academic work; $t_{f}$ - is quantity of hours of methodological work that is planned to improve quality of academic work; $t_{g}-$ is quantity of hours of types scientific work that is planned for the academic year; $\alpha_{g}-$ is planned number of results of the type of scientific work; $q_{g}$ is planned number of co-authors for the result of the type of scientific work; $t_{i}-$ is quantity of hours of organizational and educational work that is planned for the academic year.

Equation (2) must be met subject to the conditions:

$$
\left\{\begin{array}{l}
0<\alpha_{e} \leq 1 \\
t_{a b c}, t_{d}, t_{f}, t_{g}, t_{i}, \alpha_{g}>0 ; \\
q_{g} \geq 1 ; \\
t_{a b c}, t_{d}, t_{f}, t_{g}, t_{i}, \alpha_{g}, q_{g} \in Z .
\end{array}\right.
$$

As a result of Step 5, a list of the following precedents of the function under study was obtained:

- forming document section "position and stake";

- quantification of hours of education work planned for the academic year;

- forming document section "education work";

- quantification of hours of methodological work that is planned to successful completion of the academic work;

- quantification of hours of methodological work that is planned to improve quality of academic work;

- forming document section "educate-methodical work";

- quantification of hours of scientific work planned for the academic year;

- forming document section "scientific work";

- quantification of hours of organizational and educational work planned for the academic year;

- forming document section "organizational and educational work";

- forming document section "final distribution of time by type of work for the academic year".

\section{CONCLUSIONS}

The proposed technique allows to increase the accuracy of determining individual cases for describing scenarios for the implementation of functional requirements for IS. The consequence of applying this methodology in the process of collecting requirements from stakeholders will be a reduction in the number of errors in the identification of duplicate scenarios.

\section{REFERENCES}

[1] Modeling user requirements. Available at: https://docs.microsoft.com/ru$\mathrm{ru} /$ visualstudio/modeling/model-user-requirements?view=vs-2015

[2] T. Ambreen, N. Ikram, M. Usman, M. Niazi. "Empirical research in requirements engineering: trends and opportunities," Requirements Engineering, vol. 23 (1), pp. 63-95, 2018. doi: https://doi.org/10.1007/s00766-016-0258-2

[3] H. Kaiya, K. Adachi, Y. Chubachi. 'Requirements Exploration by Comparing and Combining Models of Different Information Systems, Knowledge-Based Software Engineering: 2108, pp. 64-74, 2019. doi: https://doi.org/10.1007/978-3-319-97679-2_7

[4] S.-K. Kim, T. Myers, M.-F. Wendland, P.A. Lindsay. 'Execution of natural language requirements using State Machines synthesised from Behavior Trees,' Journal of Systems and Software, vol. 85 (11), pp. 2652-2664, 2012. doi: https://doi.org/10.1016/j.jss.2012.06.013

[5] M. Ievlanov, N. Vasiltcova, I. Panforova. "Development of methods for the analysis of functional requirements to an information system for consistency and illogicality," Eastern-European Journal of Enterprise Technologies, vol. 1 , no. 2 (91)), pp. 4-11, 2018. doi: https://doi.org/10.15587/1729-4061.2018.121849

[6] M.Q. Mohammed, S.Q. Muhamed, M. Ievlanov, Z. Gazetdinova. "Improvement of the method of scenario analysis of functional requirements to an information systems," Eastern-European Journal of Enterprise Technologies.vol. 3, no. 2 (99), pp. 25-35, 2019. doi: https://doi.org/10.15587/1729-4061.2019.170351 